\title{
Força de inércia: aprofundando o debate ${ }^{+*}$
}

\author{
João Paulo Martins de Castro Chaib ${ }^{1}$ \\ Matheus da Costa Aguiar ${ }^{2}$ \\ Universidade Católica de Brasília \\ Brasília - DF
}

\section{Resumo}

Os axiomas da mecânica clássica apresentados na maioria dos livros didáticos são mostrados como o resumo dos princípios básicos das leis de Newton. No entanto, estes não são enunciados como originalmente concebido e essa mudança de palavras adapta os conceitos originais causando uma mistura de ideias. Tendo em vista esse cenário, este trabalho tem a intenção de aprofundar o debate sobre a realidade da força de inércia, buscando o conceito de vis insita que Newton concebeu, e discutir os fenômenos inerciais evidenciados nos experimentos que desenvolvemos.

Palavras-chave: Força de Inércia; Newton; Experimentos; Força Fictícia.

\begin{abstract}
The axioms of the classical mechanics presented in most textbooks are shown as the summary of the basics of Newton's laws. However, they are not enunciated as originally conceived, and this change of words adapts the originals concepts causing a mix of ideas. In view of this scenario, this work has the intent to deepen the debate of the reality of the inertial force, by seeking for the concept of vis insita, that Newton conceived, and by analyzing the inertial phenomena shown in the experiments which we developed.
\end{abstract}

\footnotetext{
${ }^{+}$Inertial force: deepening the debate

* Recebido: agosto de 2015. Aceito: novembro de 2015.

1 E-mail: jopachaib@gmail.com

2 E-mail: matheusfs.ucb@gmail.com
} 
Keywords: Force of Inertia; Newton; Experiments; Fictitious Force.

\title{
I. Introdução
}

O conceito de movimento e suas causas sofreram grandes mudanças ao longo dos séculos, desde as teorias aristotélicas até o estabelecimento da ciência moderna. Entre as contribuições de grande impacto para este estudo estão as teorias e métodos de Newton publicados em seu livro Philosophice Naturalis Principia Mathematica (Princípios Matemáticos de Filosofia Natural) (NEWTON, 1726), ou Principia, sendo este alvo de muitas críticas e estudos ${ }^{3}$.

Nos livros de consulta de hoje apresentam-se como leis de Newton conceitos que foram modificados através da história para se enquadrar dentro dos requisitos epistemológicos e didáticos que vigoram nos tempos atuais. Newton introduziu os conceitos de força motriz impressa e de força de inércia para modelar a causa do movimento e sua mudança. Este último conceito está explícito na Definição III do Principia e hoje em dia esta força é denominada em quase todos os livros didáticos de força fictícia, tal como em Symon (1986, p. 149). Por conta desta classificação, a discussão ao redor da realidade desta força é tratada de maneira confusa:

\begin{abstract}
A simplificação do debate filosófico em torno dessa questão crucial da física clássica e moderna presente hoje em livros didáticos [...] e mesmo no debate cientifico contemporâneo, tem colocado a importância do tema em pequenas e raríssimas notas de rodapé [...]. As forças ditas fictícias precisam de um tratamento que exponha os estudantes ao grande debate filosófico sobre a realidade dessas forças, debate esse iniciado por Ernst Mach [...] (NEVES, 2000, p. 1265).
\end{abstract}

O físico Ernst Mach (1838-1916), e outros filósofos naturais como George Berkeley (1685-1753) e Gottfried Wilhem Leibniz (1646-1716), propuseram ideias alternativas para a origem das forças inerciais.

Encorajados por estas diferentes visões, pretendemos aqui atender ao chamado de $\mathrm{Ne}$ ves (2000) acima citado, e desenvolver esta discussão já levantada há muito tempo, mas que ainda não foi esgotada. Deste modo, revisaremos de maneira detalhada a visão newtoniana de inércia e evidenciaremos alguns efeitos inerciais a partir de experimentos por nós elaborados no laboratório da Universidade Católica de Brasília.

\section{Axiomas ou Leis de Movimento}

Na maioria dos livros contemporâneos que tratam da Mecânica Clássica, observa-se que os princípios da Mecânica Newtoniana são enunciados da seguinte forma:

\footnotetext{
3 A primeira edição do Principia foi publicada em latim em 1687. Em 1713, Newton publica uma segunda edição corrigida. A edição em latim de 1726 é uma reedição desta versão.
} 
1. Todo corpo permanece em estado de repouso ou de movimento uniforme, em linha reta, a menos que seja obrigado a mudá-lo por forças aplicadas sobre ele.

2. A taxa de variação de momento linear é proporcional à força aplicada, e na direção em que a força age.

3. Para cada ação existe sempre uma reação igual e oposta (SYMON, 1986, p. 26).

As leis de movimento de acordo com Newton no Principia:

Lei I: Todo o corpo persevera no seu estado de repouso ou de movimento uniforme em linha recta, a não ser na medida em que é obrigado a mudar o seu estado pelas forças que lhe são impressas. [...]

Lei II: A mudança de movimento é proporcional à força motriz impressa, e dá-se ao longo da linha recta em que aquela força é impressa. [...]

Lei III: A uma ação corresponde sempre uma reacção contrária e igual: ou seja, as ações de dois corpos entre si são sempre iguais e vão em direções contrárias (BALOLA, 2010, p. 32-33).

Nestas duas versões, se observa na primeira lei uma diferença que de início aparenta ter pouca importância. Na primeira versão é lido que o "corpo permanece em estado de repouso ou de movimento" enquanto que a outra afirma que o "corpo persevera em estado de repouso ou de movimento"4.

Uma vez que na versão em latim lê-se "Corpus omne perseverare in statu suo" (NEWTON, 1726, p. 13), e na primeira versão traduzida para o inglês lê-se "Every body perseveres in its state of rest, or of uniform motion" (NEWTON, 1729, p. 19), entendemos que a última forma de traduzir é a mais apropriada.

Apesar da possibilidade de tratar estes verbos em alguns casos como sinônimos, o verbo permanecer remete o sujeito (ou o objeto físico) a um estado passivo sem necessariamente apresentar resistência, enquanto que o verbo perseverar indica um estado ativo do sujeito. Ainda, o verbo perseverar é usado comumente no Novo Testamento onde se atribui o conceito de manter-se constante apesar das forças contrárias ${ }^{5}$. Assim, sabendo de sua formação religiosa, ${ }^{6}$ e a forma como conceitua a força inercial em sua Definição III, acreditamos que Newton utilizou este termo dentro deste significado mais característico.

\footnotetext{
${ }^{4}$ Na versão original em inglês de Symon (1960), a primeira lei está escrita da seguinte forma: "Every body continues in its state of rest or uniform motion [...]".

5 Tal como, "E sereis odiados por causa do meu nome. Aquele, porém, que perseverar até o fim, esse será salvo."(Mt 10,22) e "E pelo crescimento da iniquidade, o amor de muitos se esfriará. Aquele, porém, que perseverar até o fim, esse será salvo.” (Mt 24,12-13) (GORGULHO; STORNIOLO; ANDERSON, 1991).

6 Inclusive, Newton chama a atenção no Principia daqueles que confundem as grandezas mensuráveis e relativas com as grandezas puras e absolutas pois, segundo ele, "fazem injúria às Sagradas Escrituras" (NEWTON, 1729, p. 17, tradução nossa). Acreditamos que Newton faz um suposto vínculo entre a obra divina e as grandezas absolutas.
} 
Destacamos que a primeira lei diz que um corpo não alterará seu estado de movimento uniforme se não houver força impressa, mas o oposto não é necessariamente verdade. Ou seja, a interpretação segundo a qual se diz que se há uma força impressa resultante diferente de zero sobre o corpo este irá alterar seu estado de movimento não é, necessariamente, um resultado verdadeiro.

Veja-se o exemplo de um corpo sobre uma superfície móvel plana, os quais estão em repouso relativo entre si e a um observador externo, tal como uma taça sobre um pano em um truque de mágica. Pode-se imprimir ao pano uma aceleração na qual, mesmo existindo uma força resultante impressa sobre o corpo diferente de zero, que corresponde ao atrito estático do pano sobre a taça, esta última não altera seu estado de movimento com relação ao mágico ou a mesa.

Para dar conta deste fenômeno, Newton introduziu o conceito de força inata ou inerente - que não é impressa. Ou seja, existe uma força inerente à taça que a mantém em seu estado de movimento uniforme (no caso, o repouso) apesar de existir uma força contrária de atrito (estático no primeiro momento e dinâmico no segundo momento) do pano sobre a taça. $\mathrm{E}$ apesar de muitas vezes a primeira lei ser chamada erroneamente de "Princípio da Inércia" (BONJORNO et al., 2001, p. 89), não é neste momento que Newton se refere explicitamente ao termo força de inércia.

$\mathrm{Na}$ verdade, nos parece que a primeira lei vem como uma reafirmação de uma posição filosófica e uma crítica aos que acreditavam que a "Resistência é normalmente atribuída a corpos em repouso e impulso aos em movimento", (NEWTON, 1729, p. 3, tradução nossa), uma vez que a discussão a respeito do impulso, lugar natural, inatividade da massa, e quantidade de movimento ainda estava em voga. Nesta lei, ele afirma que tanto os corpos em repouso como os em movimento uniforme, possuem as mesmas características frente a sua dinâmica.

\section{Vis Inertia}

O conceito de força de inércia é enunciado na Definição III do Principia ${ }^{7}$ :

\footnotetext{
${ }^{7}$ Esta é uma tradução que fizemos da primeira edição do inglês. Dada a maneira diferente como outros autores traduziram este trecho, achamos melhor exibir no original de 1729, com um adendo entre colchetes do original em latim:

Vis Insita, or Innate Force of Matter, is a power of resisting, by which every body, as much as in it lies, endeavours to persevere [perseverat in statu suo] in its present state, whether it be of rest, or of moving uniformly forward in a right line.

This force is ever proportional to the body whose force it is; and differs nothing from the inactivity of the Mass, but in our manner of conceiving it. A body from the inactivity of matter, is not without difficulty put cut of its state of rest or motion. Upon which account, this Vis insita, may, by a most significant name, be called Vis Inertia, or Force of Inactivity. But a body exerts this force only, when another force impressed upon it, endeavours to change its condition; and the exercise of this force may be considered both as resistance and impulse: It is resistance in so far as the body, for maintaining its present state withstands the force impressed; it is impulse, in so far
} 
A vis insita, ou força inata da matéria, é um poder de resistir, através do qual todo o corpo, assim como se encontra, esforça-se em perseverar nesse estado, seja ele de repouso ou de movimento uniforme em linha reta.

Esta força é sempre proporcional ao corpo cuja força se manifesta e não difere em nada da inatividade da massa a não ser pela maneira de concebê-la. Não é sem dificuldade imposta [que se] encerra o estado de repouso ou de movimento de um corpo vindo da inatividade da matéria. Levando isso em conta, esta Vis insita pode, por ter um nome mais significante, ser chamada Vis inertia, ou Força de inatividade. Mas um corpo exerce esta força somente quando outra força impressa sobre ele se esforça para mudar sua condição; e o exercício desta força pode ser considerado tanto como resistência como impulso: É de resistência, na medida que o corpo-para manter seu estado presente - se estabelece em oposição à força impressa; é de impulso, na medida que um corpo para não se deixar vencer facilmente pela força impressa por outro - se esforça em mudar o estado deste outro (NEWTON, 1729, p. 2-3, tradução e ênfase nossa).

Newton explicita que existe uma vis insita ou força intrínseca a todos os corpos. Esta força de inércia é exibida pelo corpo em questão no mesmo momento em que surge uma força impressa sobre ele. Além do mais, o exercício desta força de inércia aparece no sentido contrário ao da força impressa.

A força impressa sobre um corpo é o nome dado à resultante da soma dos tipos de interações a que acostumamos atribuir uma origem - gravitacional, elástica, atrito, entre outras - e que obedecem à terceira lei de Newton. Destaca-se que ela também é mencionada na segunda lei.

O curioso é que, por todo o Principia, Newton afirma que a força de inércia é intrínseca ao corpo, que ela se difere dos outros tipos de forças em sua Mecânica, por não possuir uma origem material externa e, portanto, não apresentar um par ação e reação e não se submetendo à terceira lei. Talvez seja por isso que Newton tratou esta força em separado na sua concepção mecânica.

Esta origem inata defendida por Newton foi combatida por diversos estudiosos do assunto. Mach foi um dos físicos que descartou esta hipótese sugerindo que a força de inércia tinha origem da interação combinada dos demais corpos do universo com um corpo acelerado com relação a eles. Destacamos alguns trabalhos contemporâneos que buscam esta origem: (SCIAMA, 1953; MARTINS; PINHEIRO, 2008; MASHHOON, 1993; WOODWARD, 2004; ASSIS, 2013).

Mesmo assim, apesar deste aspecto único atribuído por Newton, ele nunca tratou esta força como uma força que aparenta se manifestar, porém não está lá - ou seja, uma "força fictícia", no sentido mais literal que se pode dar a esta expressão.

as the body, by not easily giving way to the impressed force of another, endeavours to change the state of that other. 
Veremos a seguir que mesmo que ao atribuir aos fenômenos inerciais apenas uma "tendência natural", deve-se admitir que esta tendência se manifesta como uma força sobre um objeto acelerado com relação a um dado referencial, que pode ser, dependendo da concepção, o espaço absoluto, o referencial inercial ou o referencial das galáxias e estrelas, o qual chamaremos de referencial universal.

\section{III.1 Força de Inércia em movimentos lineares}

Ao se observar os movimentos lineares atentamente percebe-se com mais frequência um comportamento resistivo de um dado corpo à mudança de estado de movimento que outro corpo tenta lhe impor. No documentário The pleasure of finding of things out, produzido pela BBC em 19818, Richard Feynman, detentor do prêmio Nobel de Física de 1965, relata como percebeu a existência de fenômenos inerciais quando criança:

[...] um dia eu estava brincando com o que a gente chama de express wagon, o qual consiste em uma pequena carroça [puxada à mão] gradeada em volta [e aberta em cima] para as crianças brincarem com aquilo que podem carregar por aí. Tinha uma bola dentro dele - Eu me lembro disso - Tinha uma bola nele, e eu puxei o carrinho, logo percebi algo sobre o modo como a bola tinha se movido, então fui até meu pai e falei, "Ei pai, eu percebi uma coisa: Quando puxo a carroça a bola rola para o fundo da carroça, e quando puxo junto com a carroça e paro de repente, a bola rola para frente dela." Daí perguntei “o que é isso?” E ele disse, “ninguém sabe. O princípio geral é que as coisas que estão se movendo tendem a permanecer em movimento e as coisas que estão paradas tendem a continuar paradas a não ser que as force." e ele falou "Essa tendência é chamada de Inércia, mas ninguém sabe o que é na verdade." Agora isso é de um entendimento profundo - ele não me deu [apenas] um nome, ele sabia a diferença entre saber um nome de algo e conhecer algo, o que eu aprendi bem cedo. Foi mais a fundo e disse "Se olhar mais atentamente, descobrirá que a bola não rola até o fundo da carroça, e sim o fundo da carroça que está sendo puxado contra a bola; que a bola permanece parada como aliás na realidade se move para frente devido ao atrito e não para o fundo da carroça. " Então corri até a pequena carroça, posicionei a bola de novo e puxei a carroça por baixo, olhandoa pelos lados e vendo que na verdade ele estava certo - a bola nunca se moveu para trás da carroça quando a empurrei para frente. Ela se moveu para trás em relação ao vagão, mas em relação à calçada ela se moveu para frente um pouco, porque o vagão a carregou com ele [...] (ROBBINS, 2000, tradução nossa).

Segue um experimento e sua análise para discutir mais a fundo o que Feynman observou quando criança.

\footnotetext{
${ }^{8}$ A entrevista pode ser assistida em inglês no site da BBC no link: $<$ http://www.bbc.co.uk/ programmes/p018dvyg >.
} 


\section{III.2 Experimento 1 - o carrinho no Skate}

A fim de ilustrar uma situação na qual a força de inércia se apresenta de maneira resistiva, elaboramos um simples experimento utilizando um carrinho de brinquedo, um skate e um isopor para excluirmos o referencial externo'.

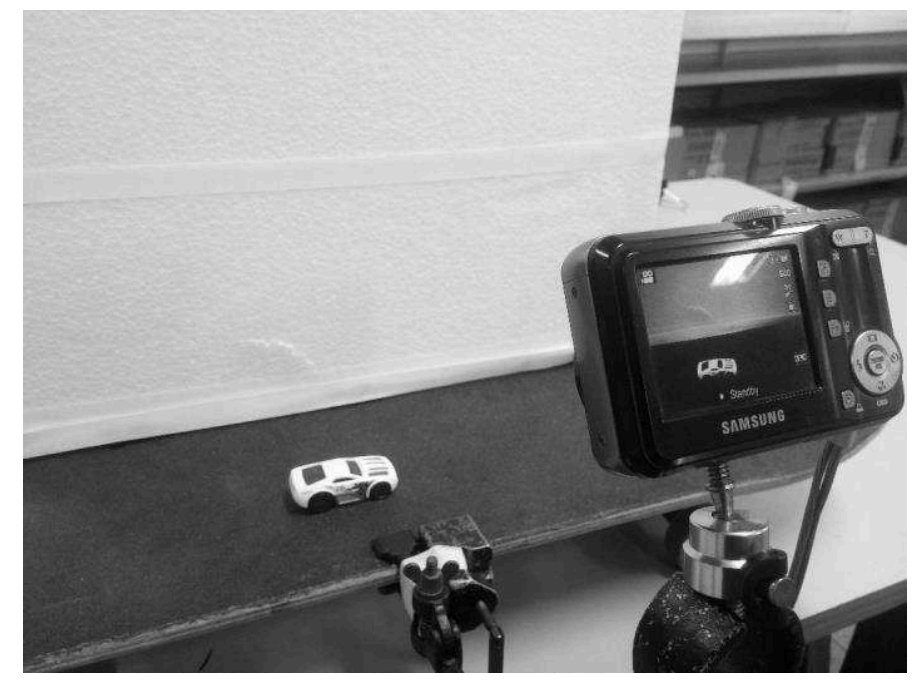

Fig. 1 - Foto do experimento.

Acelerando o skate intensamente para frente e para trás, é possível observar o comportamento do carrinho de duas perspectivas diferentes.

Olhando do ponto de vista da câmera presa ao skate, vê-se que o carrinho acelera em diversos sentidos. Ou seja, deste referencial tem-se a percepção de uma força agindo sobre o corpo que altera seu estado de movimento.

Se olharmos do ponto de vista do laboratório - com a câmera fora da montagem vista na Fig. 1 - percebe-se neste referencial que ao puxar ou empurrar o skate, o carrinho permanece em seu lugar em boa parte do tempo, sendo a sua pequena mudança de movimento atribuída ao atrito entre ele e a plataforma, tal como o movimento da bola que o próprio Feynman percebeu. No final do vídeo, observa-se um pêndulo sobre o carrinho (ver Fig. 2) e vê-se que os dois aceleram da mesma maneira (ou melhor, eles permanecem no mesmo lugar na perspectiva do laboratório). No pêndulo ocorre uma força de tração no fio - podendo inclusive arrebentá-lo mas, a princípio, não há nenhuma origem aparente para esta força.

Para modelar os fenômenos observados no referencial da câmera presa ao skate, devese levar em consideração uma força promovendo a mudança de movimento tanto no carrinho como no pêndulo apesar das forças contrárias. No referencial do laboratório, deve-se considerar uma força impedindo o movimento apesar das forças em contrário. No truque do pano puxado citado como exemplo, a princípio, só se alguém ou algo fizesse uma força contrária à força do

${ }^{9} \mathrm{O}$ vídeo do experimento está disponível no link: <https://www.youtube.com/watch?v= yibMmBJtG1w>. 
pano sobre a taça - segurando-a - que ela não seria puxada através da força de atrito estático. Da mesma forma, somente se alguém puxasse o pêndulo é que o fio tracionaria, possuindo uma componente de tração horizontal.

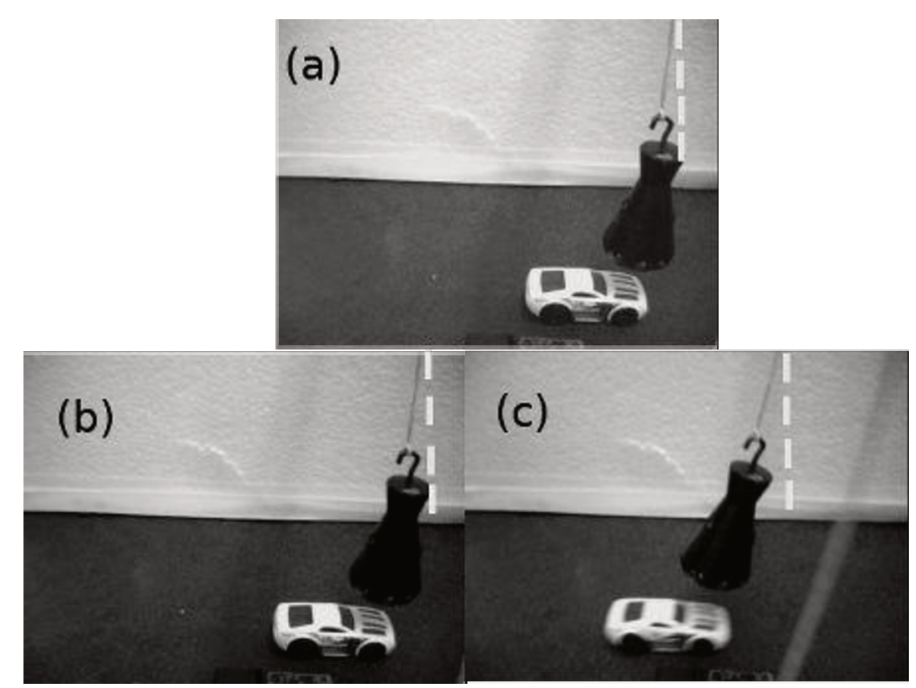

Fig. 2 - Pêndulo preso ao skate e sobre o carrinho. O skate é acelerado da perspectiva do laboratório.

Vê-se que é necessário, nos diferentes referenciais, descrever os fenômenos através de forças, independente de saber sua origem externa ou mesmo se a força aparece como uma "perseverança inerente" do corpo.

No entanto, com a discussão desenvolvida até aqui, é possível que alguém afirme que a permanência dos corpos deve-se somente a uma "tendência natural" e nada tem a ver com uma força, seja uma força do corpo inata - tal como o Newton assumiu - ou uma força sobre o corpo tendo uma origem material externa - tal como Mach defendia - pois não apresentaria outras consequências dinâmicas a não ser a permanência em seu estado de velocidade uniforme inicial com relação ao referencial universal.

Para aprofundar esta discussão, observaremos o experimento a seguir.

\section{III.2 Experimento 2 - A balança e a inércia}

Neste experimento utilizamos um corpo de massa qualquer (um pequeno pote de tinta guaxe), uma proveta com água e uma balança de precisão. Colocamos a proveta com água e o pote em cima da balança e zeramos a sua escala usando a função tare. Em seguida, soltamos o pequeno objeto dentro da proveta de uma altura significativa (Fig. 3) ${ }^{10}$.

\footnotetext{
$10 \mathrm{O}$ vídeo do experimento está disponível no link: <https://www.youtube.com/watch?v= tOQb49KVMx0>.
} 
Observou-se que sempre que o objeto mergulhava na água, a balança marcava um valor de massa acima de zero, e voltando a zero assim que pote atingia o repouso. Em um dos procedimentos filmados, a balança apresentou o valor de 5,0 g antes de voltar ao equilíbrio e marcar $-1,0 \mathrm{~g}$ (um pouco de água escapou da proveta por conta do impacto do mergulho).

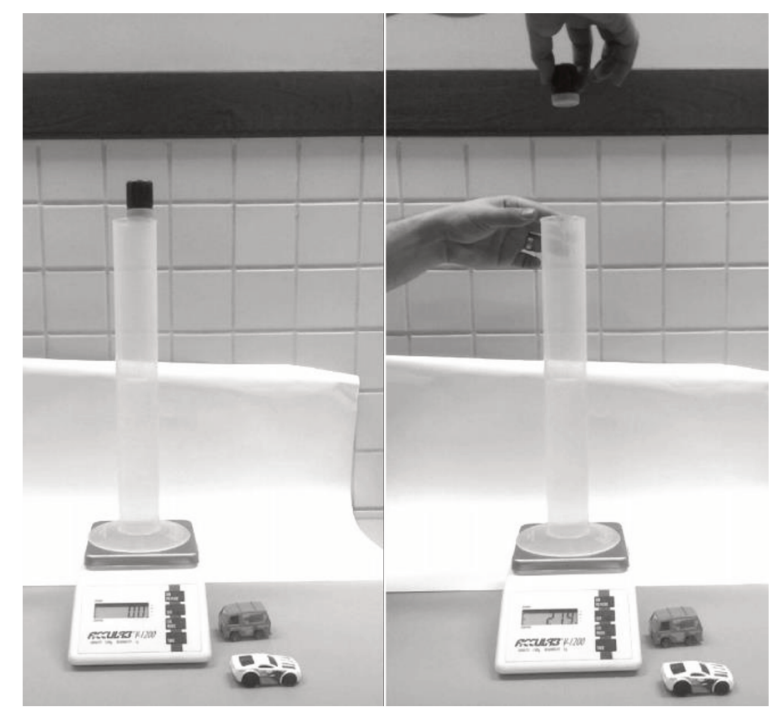

Fig. 3 - Experimento onde demonstra o efeito da força de inércia de maneira quantitativa.

O que fez com que a balança "se enganasse" e marcasse uma quantidade de massa acima da que existia realmente? Normalmente este efeito é observado apenas se alguma outra força de origem externa for impressa sobre a plataforma da balança além da força peso. Destacamos que a marca de 5,0 g também aparece no momento em que o copinho é acelerado do fundo para a superfície da água, indicando ainda a existência de uma força com o sentido contrário da aceleração.

Alguém poderia afirmar que a velocidade ou a aceleração é que causou quantidade de massa marcada a mais pela balança. Poderia a mudança de velocidade causar algo? Não é exatamente o contrário? Entendemos aqui que a mudança da velocidade é o efeito observado por conta de uma interação. Da mesma forma, acreditamos que seria inconsistente afirmar que "a energia cinética" é responsável pela força a mais, pois nisso está se afirmando que a energia cinética - que é uma característica do pote - exerce uma força. É curioso observar que, de certa forma, estes argumentos estão admitindo que o próprio pote é que exerce esta força a mais sem atribuir a ele esta faculdade de forma explícita, mas sim às grandezas que o caracterizam.

Ainda pode-se afirmar que a força de empuxo ou a reação a ela na água é responsável por esta aferição. Primeiramente a balança demonstrou vários valores diferentes para a suposta massa "a mais". E, notavelmente, cada valor era diretamente proporcional à aceleração impressa ao copinho no instante da aferição. No entanto, a força de empuxo da água sobre o copinho é proporcional ao volume submerso do objeto, e esta força atinge o valor constante depois que o copo afunda completamente. Mas o mais importante é que, para que qualquer uma das 
forças - que resultam na força impressa sobre o copo - seja responsável pelo efeito, esta precisaria violar a terceira lei de Newton. Isto seria como, por exemplo, admitir que uma pessoa com uma vara em cima de uma balança fazendo força contra a plataforma da mesma, possa alterar a medida de seu peso.

Este exemplo tem sua contraparte com o exercício clássico de física em que uma balança dentro de um elevador é acelerada junto com o corpo em cima, e marca um valor maior da massa se comparado quando o elevador está em movimento uniforme. Uma pequena análise deste exercício é feita mais a frente.

Destacamos as palavras de Newton quando tratou do movimento de um objeto em um meio resistivo sem outras forças motrizes impressas no corpo, explicitando muito bem o papel da força inercial:

Se um corpo for resistido parcialmente na razão e parcialmente com o quadrado da razão de sua velocidade, e se move num meio similar apenas por sua força inata; e os tempos forem tomados numa progressão aritmética: então quantidades inversamente proporcionais às velocidades, aumentadas por uma certa quantidade dada, estarão em uma progressão geométrica (NEWTON, 2008, nossa ênfase).

Uma vez que o empuxo é igual à força peso do copinho somente quando este tem uma parte bem pequena de seu volume fora da água. Assim, o módulo da força de empuxo é maior que a força peso quando o copo está completamente submerso. Agora, o fato de o copo submergir completamente indica a existência de uma força que se somou com a força peso. Não sendo possível identificar a origem externa desta força do ponto de vista newtoniano, o lorde inglês se satisfez em assumir que ela é intrínseca ao corpo, mas nem por isso ela deixava de ser real.

Da mesma forma, como já destacamos, diversos físicos não questionaram a sua realidade. O que se discutia era o inatismo atribuído por Newton à origem desta força e qual seria a fonte externa de interação provável que a geraria.

Mais uma vez alguém pode afirmar que esta força é considerada fictícia por conta de não promover de forma ativa a mudança no movimento relativo, por ser uma "força passiva". No entanto, este argumento deveria incluir as forças de atrito dinâmico, viscosidade ou arrasto como forças fictícias. Novamente pode-se afirmar que não é uma força real convencional por depender da mudança de movimento com relação a um referencial universal. Este argumento deveria incluir também a força eletromagnética de um ímã sobre um corpo carregado, uma vez que ela é proporcional à velocidade deste corpo.

$\mathrm{Na}$ verdade, a diferença crucial entre estas forças citadas e a força de inércia é que se atribui uma origem externa para elas. Este problema ficou em segundo plano no século XX frente o nascimento e desenvolvimento das novas vertentes que geraram a física moderna. 


\section{III.4 Força de Inércia no movimento circular}

Dada a sua concepção filosófica - que entendia a existência de uma entidade divina, absoluta e eterna - Newton concebeu a existência de dois tipos de movimentos: o movimento absoluto - ou mudança de posição em relação a um espaço absoluto - e o movimento relativo - movimento aparente para um observador em um dado referencial sem, necessariamente estar se movendo com relação ao espaço absoluto. Para justificar a existência de um referencial universal, ele utiliza a existência das forças inerciais em um sistema com movimento curvilíneo para distinguir se o movimento não é ou é puramente relativo - da mesma forma que usamos as forças inerciais para distinguir se um objeto não está ou está em um referencial inercial ${ }^{11}$ :

Os efeitos que distinguem o movimento absoluto do relativo são as forças que afastam do eixo do movimento circular [sunt vires recedendi ab axe motus circularis]. Estas forças não existem em um movimento circular puramente relativo, porém no verdadeiro e absoluto movimento circular, elas são maiores ou menores, de acordo com a quantidade de movimento (NEWTON, 1729, p. 15, tradução nossa).

Sublinhamos que nos movimentos lineares também se apresentam fenômenos inerciais. Newton usa este fenômeno apenas como a maneira mais clara de se determinar a existência dos dois tipos de movimentos. Desta forma, Newton afirma que em um movimento puramente relativo, a força inercial não se apresenta como fenômeno sobre o objeto observado em movimento.

Se imaginarmos uma pessoa dentro de um carrossel (P1) em movimento e outra do lado de fora (P2), quem estiver no ponto de vista de P1 observará uma mudança da direção da velocidade de P2, realizando um movimento circular, assim como vemos o Sol se levantar e se pôr. Mas não se observa nenhum tipo de comportamento de P2 que sugira a existência de uma força sobre ele. Assim, a pessoa dentro do carrossel pode concluir que está vendo um movimento curvilíneo puramente relativo de P2.

Na experiência conhecida como $O$ Balde de Newton - onde um balde com água gira ao redor de seu eixo de simetria - a água se move de modo a ser comprimida contra as paredes do recipiente. Além do mais, o movimento da água é percebido nos dois referenciais relativos: o que gira com o balde e o que vê o balde girar. Segundo o próprio Newton, o movimento da água no balde se dá por conta da existência de uma força real que afasta o fluido de seu eixo de rotação, assim pode-se afirmar que seu movimento circular é absoluto, ao contrário do movimento circular de P2 observado por P1 no parágrafo anterior.

Usando deste entendimento da Mecânica Newtoniana, a medida do achatamento dos polos da Terra mais o pêndulo de Foucault seriam dois dos poucos métodos experimentais dentro do planeta - de se demonstrar que a Terra gira ao redor de seu eixo. Nesta concepção,

\footnotetext{
11 Adicionamos entre colchetes o trecho do original em latim, (NEWTON, 1726, p. 10). Nesta parte consta o verbo recedere que se remete ao ato de "ir para longe".
} 
não haveria motivo para a Terra ter sua forma achatada se o movimento absoluto fosse da abóboda celeste e não do planeta. Da mesma forma, se a Terra não girasse, o pêndulo de Foucault manteria seu plano de oscilação constante no referencial terrestre durante as 24 horas. Mas, experimentalmente, se observa que o plano de oscilação do pêndulo é forçado a acompanhar fielmente o giro das constelações por todas as 24 horas que se passariam, e isto seria por conta - dentro de uma perspectiva newtoniana - da força inata que o mantêm assim, e como esta força surge somente na presença de movimentos absolutos, então é a Terra que gira.

É importante destacar mais uma vez que o experimento do balde foi feito por Newton para definir e diferenciar os movimentos relativos dos movimentos absolutos. Estes últimos são movimentos com relação a um referencial universal e sem, para Newton, materialidade, ou melhor, "sem relação com qualquer coisa externa", chamado de espaço imóvel ou espaço absoluto. Desta forma, deve-se ter cuidado, pois a inferência da existência do espaço absoluto a partir da experiência do balde é indireta.

Ao relembrar a citação anterior em que Newton afirma que o corpo se move no meio resistivo apenas por sua força inata, também entendemos que é falso assumir que o filósofo da natureza tenha atribuído à causa da força inercial ao espaço absoluto. Como apontamos diversas vezes, Newton afirma que a força de inércia é do corpo nele mesmo, que é inerente aos objetos. Por mais estranho que possa parecer, apesar desta força surgir quando em movimento absoluto (em relação ao espaço absoluto!), ela não decorreria da ação do espaço absoluto, ela não apresentaria um par ação e reação na Mecânica Newtoniana.

Já citamos que diversos cientistas, no passado e no presente, discordam do inatismo da força de inércia atribuído por Newton. De fato, nós fazemos coro com eles. Mas, por outro lado, existem posições que questionam a existência de qualquer força inercial, mesmo da força direcionada radialmente e apontando no sentido em que se afasta do eixo de rotação, ou seja, uma força centrífuga:

Pela nossa leitura, trata-se da tendência em sair pela tangente, e não ao longo do raio. Se já é difícil explicar o motivo pelo qual a água sobe pelas paredes ao comprimir o balde na direção tangencial, fica quase inimaginável uma explicação devida à compressão radial (GOMES, 2007, p. 52).

Portanto, vale a pena desenvolver alguns procedimentos experimentais para aprofundar esta discussão.

\section{III.5 Experimento 3 - Carrinho na Plataforma Giratória}

Imagine três carrinhos de brinquedo dispostos em cima de uma plataforma giratória em forma de disco, de maneira a se mover apenas ao longo da linha radial deste e com o centro 
de massa afastado levemente do centro (veja Fig. 4). O que acontecerá com os carrinhos ao girar a plataforma com relação ao laboratório? ${ }^{12}$

Ao girar o disco observamos que dois dos carrinhos se moveram radialmente para fora do eixo de rotação até que escapassem da plataforma. O terceiro carrinho se manteve imóvel por conta das rodas travadas pelo atrito. Quando se vê o fenômeno em câmara lenta e se observa atentamente o movimento do carrinho logo após cair do disco, ele segue uma diagonal reta com relação ao ponto de saída e as direções radial e tangente do disco.

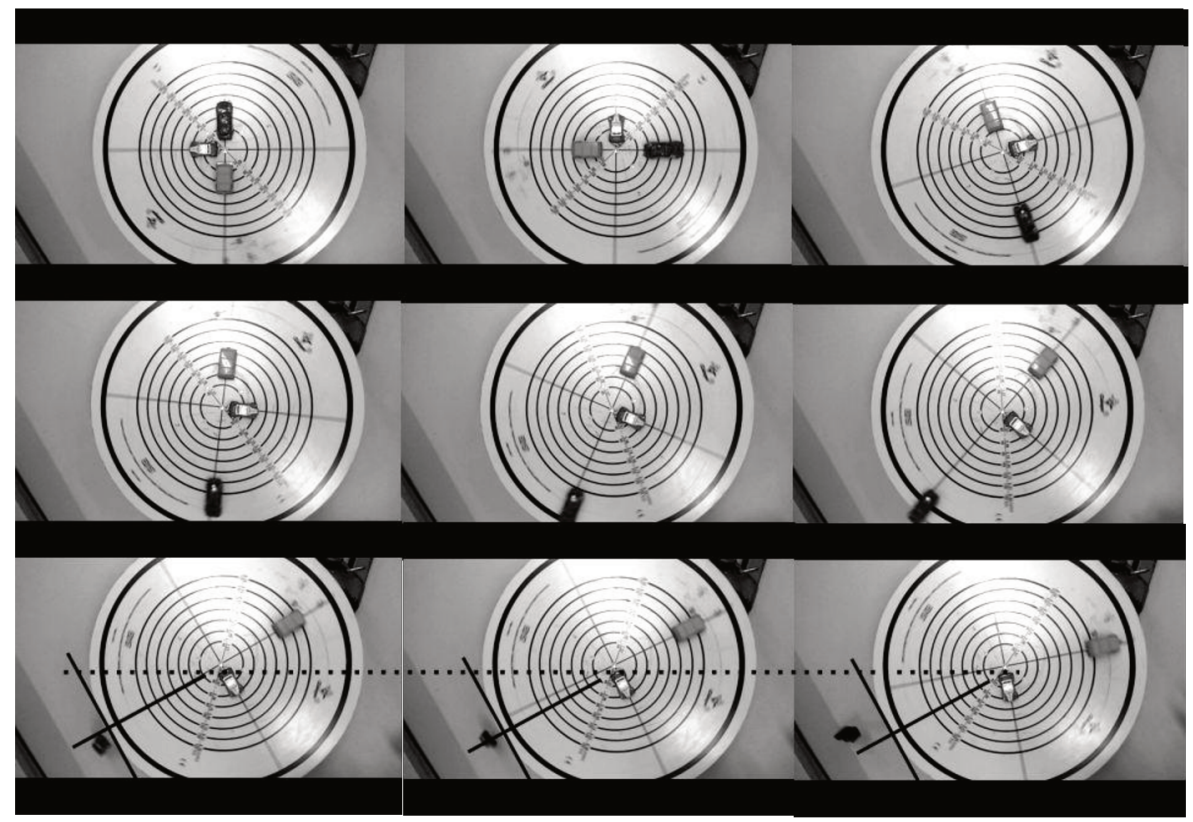

Fig. 4 - Visão superior quadro a quadro do movimento de três carrinhos de brinquedo sobre uma plataforma girante e dispostos de maneira que se desloquem somente na direção radial do disco.

Fizemos então uma variação deste experimento: agora o carrinho, disposto a percorrer apenas o sentido radial, foi preso a uma mola que está fixa no centro da plataforma giratória. Ao girar a plataforma o carrinho se moveu puxando a mola, cuja força elástica - que puxa para o centro do giro - se equilibrava com uma força - que puxava para fora do centro - de intensidade proporcional à velocidade angular da plataforma com relação ao laboratório.

$\mathrm{Na}$ montagem do experimento, o contato entre a superfície do disco e a superfície das rodas do carrinho não permite que elas deslizem, impedindo assim o movimento tangencial com relação ao disco. Se não existisse qualquer ação radial sobre os carrinhos, porque eles se deslocariam assim?

Somando o fenômeno da distensão radial da mola, vê-se um movimento ao longo do raio do disco, para fora do eixo de rotação. Ou seja, aparece uma força sobre o carrinho no

$12 \mathrm{O}$ vídeo do experimento está disponível no link: <https://www.youtube.com/watch?v= edpHWNn0Dsc>. 
sentido de fuga do centro, e o carrinho, por sua vez puxa a mola. E quanto maior a velocidade angular, maior é a força centrífuga que atua.

Descarta-se o atrito como agente desta força centrífuga, pois se não houvesse atrito, nenhum dos três carrinhos girariam com a plataforma, sendo este responsável pela força centrípeta. Da mesma forma, se o experimento fosse feito com um gelo em uma calha, se eliminaria $\mathrm{o}$ atrito, mas o efeito do gelo se afastando do centro seria o mesmo. $\mathrm{O}$ fenômeno da mola se esticando pode ser visto sem atrito nenhum. Basta encaixar uma das extremidades da mola em um eixo e girá-lo, de maneira que a mola não encoste no plano do disco.

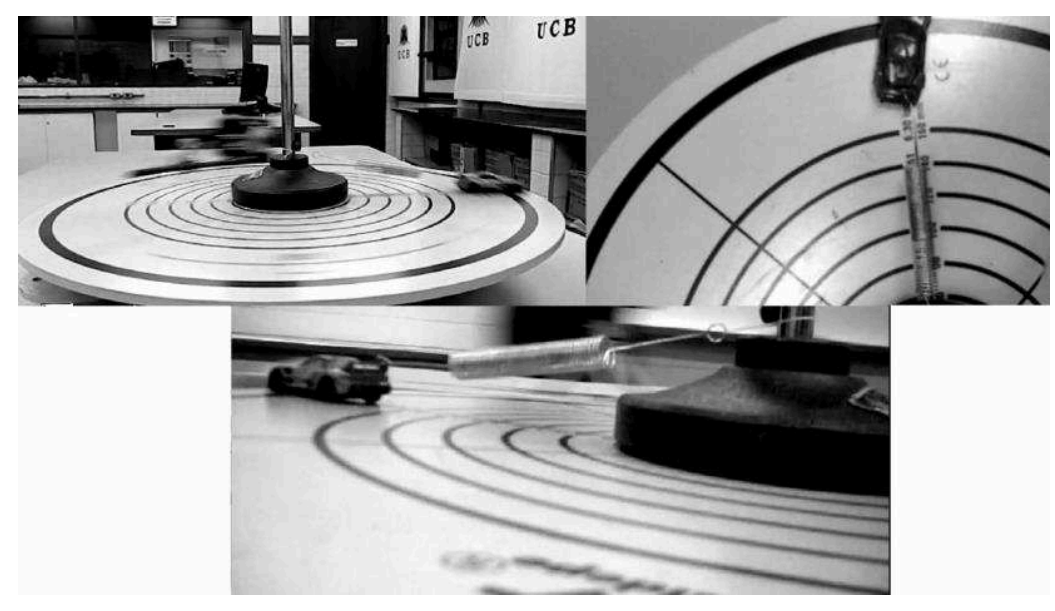

Fig. 5 - Experimento de um carrinho preso a uma mola sobre uma plataforma girante de três perspectivas diferentes.

É possível afirmar que estes fenômenos são devido a alguma "tendência natural" do carrinho permanecer no seu estado de movimento. Isto porque uma vez que se inicia a rotação, a "tendência natural de sair pela tangente" anterior do carrinho, por este ter mudado de posição, possui agora uma componente tangencial e radial com relação ao sistema do disco.

As forças geradas pelo atrito estático sobre as rodas criam um ponto de apoio e anulam a componente tangencial desta "tendência natural" uma vez que o eixo de rotação das rodas está paralelo à tangente do disco. Já a componente radial da tendência, compõe um par de forças com a força de atrito estático, surgindo um torque nas rodas e fazendo com que o carrinho se afaste do centro.

Entendemos que só forças anulam componente de forças, pois se trata de uma soma, mesmo que vetorial. Como a força de atrito pode anular a componente tangencial de uma "tendência natural" com dimensão de força? Como uma "tendência" pode compor um par de forças para criar um torque? Mais uma vez, mesmo sem querer, acaba-se por qualificar esta tendência natural do corpo em permanecer no seu estado de movimento uniforme com todas as características de uma força inata, só que sem assumir isso de forma explícita.

Suspeitamos que os termos "fictício" ou "pseudo" que foram atribuídos a essa força eram justamente para evitar o termo "inato", apesar de não se saber sua origem. No entanto, o 
que se observa é um efeito didático contrário, pois estes termos acarretaram em uma negação da realidade desta força, fazendo admitir - por não poder negar os efeitos dinâmicos (tal como a balança, os carrinhos acelerando, ou o carrinho esticando progressivamente a mola) - implicitamente a existência de uma força, só que agora chamada de "tendência natural".

Na realidade, a chamada "tendência de sair pela tangente" é observada apenas quando se anula a força centrífuga por uma componente centrípeta. Podemos citar como exemplo, um corpo girante preso por uma corda a qual é solta quando em rotação ou cortada por uma lâmina: como neste caso a força centrípeta dada pela tração da corda anula a força de inércia radial, a única componente de movimento que permanece com relação ao laboratório é a componente do movimento tangencial instantâneo. Daí, ao cortar ou arrebentar a corda, se observa o objeto fazendo um movimento retilíneo linear tangencial à curva que desenharia se ainda estivesse preso.

Outro exemplo muito comum utilizado é o de um carro derrapando durante uma curva:

Deve-se ao atrito entre os pneus e a estrada a força centrípeta necessária para conservar o carro na sua trajetória circular. Eliminando-se esse atrito, o carro por inércia, sai pela tangente, não conseguindo completar a curva (Bonjorno et al., 2001, p $115)$.

De que maneira a força de atrito do chão com o pneu é "eliminada"? Esta força some de repente? Não. Neste caso, a força centrífuga está equilibrada pela força de atrito (centrípeta) que o chão aplica sobre as rodas do carro. Se por um instante a velocidade angular do carro ultrapassar um limite máximo, a força centrífuga será maior fazendo o carro escorregar radialmente. Instantaneamente o atrito estático das rodas com o chão passará para atrito dinâmico fazendo com que o carro derrape de uma vez. Uma vez que a componente radial do movimento é ínfima se comparada à componente tangencial percebe-se apenas a "saída pela tangente".

O grande problema é que se generaliza estes dois casos experimentais citados como exemplo para todo tipo de movimento circular, o que dificulta explicar o fenômeno do liquificador, da centrífuga da máquina de lavar (que separa a água da roupa pela força centrífuga), do achatamento dos polos da Terra, entre outros fenômenos.

\section{Pequeno desenvolvimento da discussão}

É importante relembrar que, embora para Newton, a força inercial seja intrínseca ao corpo, a condição para que ela se manifeste se dá sempre quando este mesmo corpo apresenta uma aceleração instantânea com relação a um referencial universal (o espaço absoluto, ou referencial inercial, ou galáxias e estrelas, entre outros).

Consideremos o sistema da Fig. 6 em que o Bloco 1 está sobre uma plataforma sem atrito. $\mathrm{O}$ resultado interessante deste sistema é que, por mais que a única força ativa no sistema seja a força gravitacional, o sistema apresenta uma aceleração resultante diferente do valor da constante de aceleração gravitacional. Por quê? 


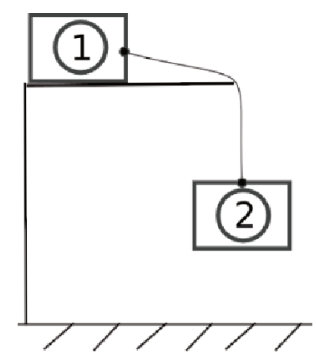

Fig. 6 -Deslizamento do Bloco 1 em um plano sem atrito e ligado a um Bloco 2 por um fio de massa desprezivel.

Da segunda lei de Newton, temos que:

$$
\Sigma \mathbf{F}=m_{\mathrm{s}} \mathbf{a} \Rightarrow \mathbf{P}_{1}+\mathbf{N}_{1}+\mathbf{T}_{1}+\mathbf{T}_{2}+\mathbf{P}_{2}=m_{s} \mathbf{a}
$$

Onde $m_{\mathrm{s}}$ é a massa total do sistema, sobre qual existe inércia, os termos $\mathbf{P}_{1}, \mathbf{N}_{1}, \mathbf{T}_{1}$ são respectivamente a força peso, a força normal do plano e a força de tração do fio sobre o Bloco 1 e $\mathbf{T}_{2}, \mathbf{P}_{2}$ são a força de tração do fio sobre o Bloco 2 e a força peso. As forças $\mathbf{P}_{1}, \mathbf{N}_{1}$ se equilibram assim como as forças $\mathbf{T}_{1}$ e $\mathbf{T}_{2}{ }^{13}$. Desta maneira, obtém-se que:

$$
\begin{gathered}
\mathbf{P}_{2}=m_{\mathrm{s}} \mathbf{a} \Rightarrow \\
m_{2} g=\left(m_{1}+m_{2}\right) a \Rightarrow \\
\Rightarrow a=g m_{2} /\left(m_{1}+m_{2}\right) .
\end{gathered}
$$

Em que $a$ é a aceleração do sistema com relação ao laboratório, $m_{1}$ e $m_{2}$ são respectivamente as massas do Bloco 1 e do Bloco 2, e $g$ é a constante de aceleração gravitacional.

Este resultado nos informa que quanto maior for a massa do Bloco 1, menor será a aceleração do sistema, apesar de não existir atrito! De maneira que se a massa do Bloco 1 for muito maior que a do Bloco 2 a aceleração do sistema tende a zero!

O que impede que $a$ seja igual à constante de aceleração gravitacional para qualquer massa do Bloco 1? Ora, se $m_{1}=0$, o Bloco 2 teria sua aceleração igual a $g$. Como a força de inércia está presente nos dois Blocos, o valor da aceleração do sistema ser menor que $g$ se dá pela força de inércia do (ou no) Bloco 1 o qual resiste de forma ativa à mudança no seu movimento. Da mesma forma, como tanto a força gravitacional quanto a inercial são proporcionais à massa de um corpo, a aceleração do sistema tende para o valor $g$, quando $m_{2}>>m_{1}$.

No caso do exemplo citado da balança dentro de um elevador acelerado, a força normal contra a plataforma da balança é igual à força peso mais a força de inércia que, segundo a visão newtoniana, o bloco faz ao resistir ao movimento acelerado, ou seja:

\footnotetext{
${ }^{13}$ Reparamos que, por conta do desenvolvimento em partes do exercício em diversos livros didáticos, alguns se confundem e atribuem esta diferença de aceleração à tração do fio, mas isto seria violar a 3a lei de Newton e assumir que um sistema mecânico fechado pode realizar força em si através da força de tração e mudar a quantidade de movimento deste sistema com relação a um referencial externo.
} 


$$
N=m a+P
$$

que é o resultado clássico.

Para entender o exemplo da taça e o pano debaixo dela, o motivo de a taça permanecer em repouso, apesar de existir a força atrito entre ela e o pano puxado, se deve entender que a condição da inércia é que caso o produto da massa pela aceleração instantânea que o pano imprimiu a ela for maior que o valor da força de atrito estático, ela permanecerá em repouso. Daí o motivo do limite superior para um objeto não derrapar sobre um plano ser quando o atrito estático for igual ao produto da massa pela aceleração impressa.

Veja-se outro exemplo de uma pedra presa em uma mola em uma superfície horizontal sem atrito. Se puxar a mola com uma dada aceleração pela outra ponta, a mola se esticará e a pedra não sairá do lugar até que o módulo da força elástica $k x$ seja igual ao produto da massa da pedra pela aceleração instantânea que se imprime.

No caso do corpo em movimento circular uniforme, mesmo a velocidade não mudando o módulo, ela muda de sentido com relação a um referencial universal e - pela velocidade ser uma grandeza vetorial - o corpo apresenta para este referencial uma aceleração que aponta para o centro. Uma vez que a aceleração se apresenta, a força de inércia também se manifestará no sentido contrário ao da aceleração. Ou seja, a força centrífuga é uma das grandes consequências dinâmicas que exibe a característica vetorial da velocidade, e que poderia ser explorada em sala de aula. Mas, ao contrário, costuma-se afirmar que ela não existe.

\section{Conclusão}

É interessante notar que a força centrífuga tem sua existência reconhecida economicamente, uma vez que este é um dos motivos que define a base em Alcântara/Brasil ser um ponto estratégico mundial para o lançamento de foguetes. Por conta de a aceleração centrípeta ser proporcional ao produto da velocidade angular pelo quadrado do raio, a força centrífuga é maior quanto mais perto do equador, exigindo menos combustível para se vencer a força centrípeta gravitacional e atingir a velocidade de escape.

Mais uma aplicação econômica deste fenômeno está na marcha automática, que usa a rotação do óleo - ligada à rotação do motor - e a força centrífuga sobre ele para realizar uma pressão hidráulica nas placas de embreagem.

Existem inúmeros exemplos que podem ilustrar a manifestação de fenômenos inerciais e, dada toda a discussão desenvolvida aqui, estamos convencidos da existência física da força de inércia. Mas ao contrário de Newton, acreditamos que esta força obedece à lei de ação e reação, apesar de não estabelecermos qual seria a sua origem externa de fato.

Mas, isso não desqualifica o debate em nada. Na verdade, este ponto é alvo de diversas pesquisas, existindo pesquisadores que atribuem a origem das forças inerciais a uma origem eletrodinâmica, (MARTINS; PINHEIRO, 2008), ao espaço de Minkowski, (MASHHOON, 1993) ou devido à ação gravitacional dos demais corpos celestes que nos cercam, (ASSIS, 2013). 
Também entendemos que se deva refletir sobre as motivações que levam a defesa da inexistência da força de inércia. Primeiramente esta concepção está longe da concepção newtoniana da Mecânica, pois para Newton ela é real apesar de inata. Seria interessante mapear quando ela surgiu.

Acreditamos que a dominação de "pseudo" ou "fictícia" terminou por acarretar em vários professores e pesquisadores o desejo de entender estas forças literalmente como são chamadas e justificar erroneamente estas denominações. No mínimo, isso pode atrapalhar o processo de ensino e aprendizagem.

Tavez seja possível para cada fenômeno inercial diferente encontrar um modelo diferente para explicá-lo. Neste sentido pensamos que valha a pena uma reflexão sobre uma frase de William de Ockham (1285-1347): “O que pode ser explicado pelo menor número de suposições é explicado em vão por mais” (Em GODU, 2008, p. 314).

Por fim, além dos aspectos didáticos e de interpretação física, o debate envolvendo a força de inércia pode trazer à tona a Física como construção humana, revelando questões epistemológicas sobre o inatismo (força inata) e a ideia de "tendência natural das coisas" - algo muito semelhante ao "lugar natural" aristotélico - e especular sobre sua possível origem externa, sendo que esta discussão pode ser bem desenvolvida no ambiente de aula.

\section{Agradecimentos}

Gostaríamos de agradecer aos professores Dr. Daniel O. Vieira Lopes, Dr. Fábio M. de Souza Lima e Dr. Fábio Ferreira Monteiro, cujo debate contribuiu enormemente para o enriquecimento deste trabalho.

\section{Referências}

ASSIS, A. K. T. Mecânica Relacional e Implementação do princípio de Mach com a Força de Weber Gravitacional. Montreal: Apeiron, 2013. 459 p. Disponível em: <http://www.ifi.unicamp.br/ assis/Mecanica-Relacional-Mach-Weber.pdf.> Acesso em: 08 ago. 2015.

BALOLA, R. Princípios matemáticos da filosofia natural: a lei da inércia. 2011. 119 f. Dissertação (Mestrado em Estudos Clássicos) - Departamento de estudos Clássicos, Faculdade de Letras, Universidade de Lisboa, Lisboa. Disponível em: < http://repositorio.ul.pt/handle/10451/5363 > Acesso em: 08 ago. 2015.

BONJORNO, R. A. et al. Física completa. 2. ed. São Paulo-SP: Ftd., 2001. 551 p.

GODU, A.; OCKHAM, W. In: KOERTGE, N. (Ed.). New Dictionary of Scientific Biography. New York: Charles Scribner's Sons, 2008. v. 5, p. 312-315. 
GOMES, L. C. O experimento do balde girante de newton: muitas perguntas, poucas respostas. Acta Scientiae, v. 9, n. 2, p. 39-63, 2007.

GORGulho, G. D. S.; STORNIOlO, I.; ANDERSON, A. F. (Ed.). A Bíblia de Jerusalém. 5. ed. São Paulo-SP: Edições Paulinas, 1991. cap. Mateus.

MARTINS, A. A.; PINHEIRO, M. J. On the electromagnetic origin of inertia and inertial mass. International Journal of Theoretical Physics, Springer, v. 47, n. 10, p. 2706-2715, 2008.

MASHHOON, B. Quantum theory and the origin of inertia. Foundations of Physics Letters, Springer, v. 6, n. 6, p. 545-559, 1993.

NEVES, M. C. D. "Conatus recedenti ab axe motus" ou a parábola do balde de newton. Acta Scientiarum. Technology, v. 22, n. 5, p. 1263-1267, 2000.

NEWTON, I. Philosophiae naturalis principia mathematica... Apud. Guil. \& Joh.Innys, 1726. Disponível em: <https://books.google.com.br/books?id=0xYOAAAAQAAJ >. Acesso em: 08 ago. 2015.

NEWTON, I. The Mathematical Principles of Natural Philosophy. Tradução: Benjamin Motte, 1729. (The Mathematical Principles of Natural Philosophy, v. 1). Disponível em: <https://books.google.com.br/books?id=b3RgvRUi2FsC>. Acesso em: 08 ago. 2015.

NEWTON, I. Principia: princípios matemáticos de filosofia natural. Livro II e III: O sistema do mundo. São Paulo: EDUSP, 2008. 448 p.

SCIAMA, D. W. On the origin of inertia. Monthly Notices of the Royal Astronomical Society, Oxford University Press, v. 113, n. 1, p. 34-42, 1953.

SYMON, K. Mechanics. Minesota: Addison-Wesley, 1960. 639 p.

SYMON, K. Mecânica. 2. ed. Rio de Janeiro: Campus, 1986. 686 p.

WOODWARD, J. F. Flux capacitors and the origin of inertia. Foundations of Physics, Springer, v. 34, n. 10, p. 1475-1514, 2004. 